\title{
What's new in pulmonary transplantation: Finding the right lung for every patient
}

\author{
John H. Dark, FRCS
}

\author{
From the Institute of Cellular Medicine, University of Newcastle, Newcastle upon Tyne, United Kingdom. \\ Disclosures: Author has nothing to disclose with regard to commercial support. \\ Received for publication Sept 2, 2015; accepted for publication Sept 3, 2015. \\ Address for reprints: John H. Dark, FRCS, Cardiothoracic Centre, Freeman Hospital, Newcastle upon Tyne \\ NE7 7DN, United Kingdom (E-mail: j.h.dark@ncl.ac.uk). \\ J Thorac Cardiovasc Surg 2016;151:315-6 \\ $0022-5223 / \$ 36.00$ \\ Copyright (c) 2016 by The American Association for Thoracic Surgery \\ http://dx.doi.org/10.1016/j.jtcvs.2015.09.024
}

Despite what should be maturity-it has been more than 50 years since Hardy's 1964 clinical case, and approaching 30 since the first successful series from Toronto-the field of lung transplantation remains beset by more unknowns than knowns.

Mortality among those on the waiting list is rising across the world; more than 400 Americans died, or became too sick for transplant, in 2012. Those most at risk were the 12- to 17-year age group, followed by the 18- to 34-year age group. ${ }^{1}$ The total numbers of lung transplants fell back slightly in the same year. Although lung utilization rates were a healthy $37 \%$ in the United States, this still means that no lungs were retrieved from almost $60 \%$ of donation after brain death donors. That figure comes close to $98 \%$ for donation after circulatory declaration of death (DCDD) donors.

No lung going through the trauma of brain death in a patient undergoing mechanical ventilation will be normal. Lung injury in the donor translates initially into an increased risk of primary graft dysfunction (PGD) in the recipient and subsequently (and this link has been proved beyond debate) into higher early and late mortalities. So on face value, the "quality" of the donor lung dictates posttransplant survival and thus the benefit of what we can offer to our patients.

This appealing but perhaps overly simplistic scenario is upset by two additional perspectives. One is that we have no robust way to define "donor lung quality"; the other is that recipient variables play an increasingly recognized role in determining early events.

A key study came from Diamond and colleagues ${ }^{2}$ of the Lung Transplant Outcomes Group in 2013. ${ }^{2}$ In an analysis of predictors of PGD, with data collected prospectively at 10 US centers, pulmonary hypertension and recipient obesity both came out as important predictors. In contrast, on the donor side, ischemic time and, crucially, the sacred cow of donor oxygenation both disappeared as risk factors. Donor smoking history, already established as a risk for 1-

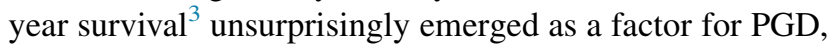
as did such intraoperative variables as the use of cardiopulmonary bypass.

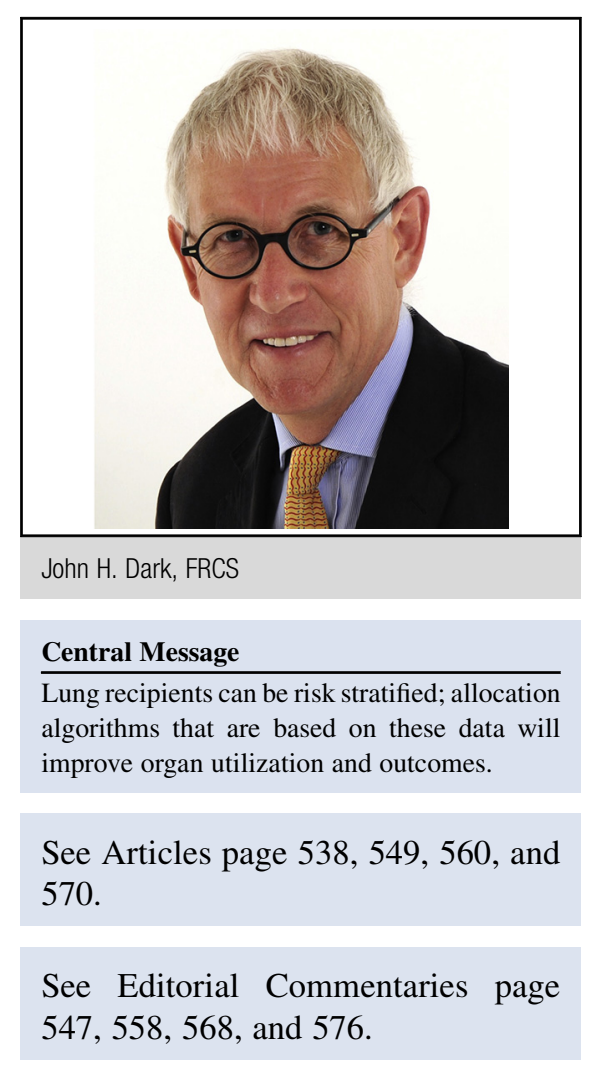

One obvious question arising from the Lung Transplant Outcomes Group study of Diamond and colleagues, whether marginal donors can be used safely for low-risk recipients, was addressed in presentation by Matthew Mulligan and colleagues from University of Maryland at the recent American Association for Thoracic Surgery annual meeting. In an analysis of United Network for Organ Sharing data, they divided donors and recipients into high- and low-risk groups for more than 12,000 transplants. Donor risk factors, which were derived from multivariate Cox proportional hazard regressions, eventually included only age, smoking history, and oxygenation less than $300 \mathrm{~mm} \mathrm{Hg}$. Only $11 \%$ of donors were high risk, but the outcome of transplants with low-risk recipients was identical to that of transplants with low-risk donors. Only the transplants from high-risk donors into high-risk recipients had less favorable results-but, crucially, still a better survival than with no transplant at all.

This was a retrospective, registry data analysis, but it is strongly supported by a key article from the very active team in Hannover. ${ }^{4}$ Within the Eurotransplant system, 
which includes Germany, initial lung offers are made to specific patients, with those in the higher urgency categories getting priority. It is a situation in which stable, nonurgent patients might have a considerable wait for a lung. These are the same individuals, however, who by modern reckoning represent low-risk recipients, lacking, for instance, pulmonary hypertension. The imaginative step taken by the Hannover group was to ensure that the best lungs went largely to the sickest patients. They were then, however, prepared to give the "rescue" lungs, already turned down by 3 other centers, to the most stable recipients. This slightly counterintuitive approach resulted in outcomes just as good as when those same patients received "standard" lungs. The finding that they had shorter ventilation times, shorter hospital stay, and identical survival out to 2 years underlines the important influence of recipient risk factors.

This approach is further supported by a more recent article from Shah and colleagues ${ }^{5}$ in the Lung Transplant Outcomes Group, describing a predictive modeling approach to identifying those most and least at risk for PGD. The latter were in a cohort that included nonobese patients with a diagnosis of chronic obstructive pulmonary disease or cystic fibrosis and an absence of severe pulmonary hypertension. This group had a PGD incidence of less than $5 \%$, and the success was not affected if, for instance, the donor had a smoking history. To quote Shah and colleagues, ${ }^{5}$ "improved preoperative prediction may facilitate attempts to safely expand the donor pool by characterizing lower risk recipient groups."

Having completed this elegant and important analysis, Shah and colleagues ${ }^{5}$ displayed a disappointing conservatism by including lungs from DCDD donors and lungs from ex vivo lung perfusion (EVLP) in the extended donor category. For both these categories, the evidence is to the contrary.

A meta-analysis of published outcomes of lung transplants from DCDD donors showed no difference in survival, acute rejection, or PGD rates when compared with a contemporaneous group of lungs from donation after brain death donors. Perhaps more pertinently, there is an Australian experience of using such lungs in patients with pulmonary hypertension, already defined as a high-risk recipient group, again with equally good outcomes. ${ }^{6}$ There is only a single article, with data from just a single institution, that suggests a higher risk of bronchiolitis obliterans syndrome in the medium term. ${ }^{7}$ It thus remains to an outsider inexplicable that only 21 lung transplants, $1.2 \%$ of the total, were done with DCDD lungs in the whole of the United States in 2012. ${ }^{1}$

There is a similar story with lungs from EVLP, where there is good or even overwhelming evidence that their outcomes after transplant, when performed with current technologies and acceptance criteria, are comparable with those from standard lungs. ${ }^{8}$ Of course, major questions remain; we do not know how many lungs are truly unusable lungs and how many can be moved into the pool for safe transplant. This highlights the dearth of robust measure of donor lung quality. More than a decade ago, we demonstrated a complete disconnect between clinical assessment of the donor lung and the inflammatory load, as assessed by levels of the proinflammatory cytokine interleukin 8 . Only objective, post hoc, measures such as interleukin 8 correlated with outcome. ${ }^{\text {? }}$

We also do not know the best interventions to reverse lung injury and reduce reperfusion damage during EVLP. Work such as that presented by Cynthia Wagner and colleagues from the University of Virginia at the recent American Association for Thoracic Surgery annual meeting, which showed a major benefit from an adenosine A2A receptor agonist in lungs subjected to a DCDD injury and then 12 hours of ischemia before EVLP, is crucial. But we must remember that these experimental insults may be poor surrogates for the clinical setting, and final proof must be in lungs from real, clinical donors.

In conclusion, we can identify the high- and -risk candidates, and we should in due course tailor allocation with this information in mind. Activity can be expanded, and perhaps waiting list deaths can be reduced, with safer use of marginal lungs for low-risk recipients and more use of DCDD lungs across the board. Characterization of the good donor lung, however, either de novo or after EVLP, remains a key area for research. Too much faith has been put in what is easy to measure- $-\mathrm{PO}_{2}$ for instance-rather than on what is actually important. We need relevant, objective, and repeatable measures, which may include what we can learn during EVLP, if we are to realize the maximum benefits of lung transplantation.

\section{References}

1. Valapour M, Skeans MA, Heubner BM, Smith JM, Schnitzler MA, Hertz MI, et al. OPTN/SRTR 2012 Annual Data Report: Lung. Am J Transplant. 2014;14(Suppl 1):139-65.

2. Diamond JM, Lee JC, Kawut SM, Shah RJ, Localio AR, Bellamy SL, et al. Clinical risk factors for primary graft dysfunction after lung transplantation. Am J Respir Crit Care Med. 2013;187:527-34.

3. Bonser RS, Taylor R, Collett D, Thomas HL, Dark JH, Neuberger J, et al. Cardiothoracic Advisory Group to NHS Blood and Transplant and the Association of Lung Transplant Physicians (UK). Effect of donor smoking on survival after lung transplantation: a cohort study of a prospective registry. Lancet. 2012;380:747-55.

4. Sommer W, Kühn C, Tudorache I, Avsar M, Gottlieb J, Boethig D, et al. Extended criteria donor lungs and clinical outcome: results of an alternative allocation algorithm. J Heart Lung Transplant. 2013;32:1065-72.

5. Shah RJ, Diamond JM, Cantu E, Flesch J, Lee JC, Lederer DJ, et al. Objective estimates improve risk stratification for primary graft dysfunction after lung transplantation. Am J Transplant. 2015;15:2188-96.

6. Levvey BJ, Whitford HM, Williams TJ, Westall GP, Paraskeva M, Manterfield C, et al. Donation after circulatory determination of death lung transplantation for pulmonary arterial hypertension: passing the toughest test. Am J Transplant. 2015;15:3208-14.

7. Sabashnikov A, Patil NP, Popov AF, Soresi S, Zych B, Weymann A, et al. Longterm results after lung transplantation using organs from circulatory death donors: a propensity score-matched analysis. Eur J Cardiothorac Surg. 2016;49:46-53.

8. Andreasson AS, Dark JH, Fisher AJ. Ex vivo lung perfusion in clinical lung transplantation-state of the art. Eur J Cardiothorac Surg. 2014;46:779-88.

9. Fisher AJ, Donnelly SC, Pritchard G, Dark JH, Corris PA. Objective assessment of criteria for selection of donor lungs suitable for transplantation. Thorax. 2004;59: 434-7. 